\title{
Alcohol interacts with flavor during extinction of conditioned taste aversion
}

\author{
CHRISTOPHER L. CUNNINGHAM \\ University of Oregon Health Sciences Center, Portland, Oregon 97201
}

\begin{abstract}
Intraperitoneal injections of ethanol $(1.2 \mathrm{~g} / \mathrm{kg})$ given $30 \mathrm{~min}$ before taste-aversion extinction trials retarded extinction of aversion to a quinine-hydrochloride solution, did not affect extinction of aversions to sucrose or hydrochloric-acid solutions, but facilitated extinction of aversion to a sodium-chloride solution. These results do not support the general belief that ethanol retards extinction, but seem more consistent with the suggestion that IP injection of ethanol produces a taste which interacts with the tastes of orally ingested substances. Some implications of this possibility for the study of pharmacological agents on conditioned taste aversion are discussed.
\end{abstract}

Extinction has been retarded by ethanol in both appetitive and aversive conditioning situations (Amit, Ziskind, \& Baum, 1973; Barry, Wagner, \& Miller, 1962; Baum, 1969, 1970, 1971; Cappell, LeBlanc, \& Endrenyi, 1972; Skurdal, Eckardt, \& Brown, 1975). Inasmuch as the study by Cappell et al. is the only one of these studies which did not involve an instrumental locomotor response, it contributes importantly to the belief that these findings reflect a general effect of ethanol on the process of extinction and not simply a drug-evoked enhancement of locomotor behavior. In their study, extinction of aversion conditioned to the taste of saccharin was retarded by intraperitoneal (IP) injection of ethanol $(.6, .9,1.2 \mathrm{~g} / \mathrm{kg})$ given $30 \mathrm{~min}$ before each extinction trial. Because an equally novel drug (chlordiazepoxide) had just the opposite effect on taste-aversion extinction, Cappell et al. rejected Amit and Baum's (1970) drug-novelty explanation of retarded extinction under ethanol. Nevertheless, they conceded that the outcome of their taste-aversion study was consistent with a belief that the ethanol state is aversive. However, they also reported that ethanol did not suppress saccharin drinking in nonconditioned animals, and the possibility remained that ethanol exerted its effect through some as yet unspecified mechanism(s).

The present experiments were intended to examine further ethanol's apparent ability to retard extinction of conditioned taste aversion. They were designed to verify the general findings of Cappell et al. and to extend them in two ways: first, by using different

This research was supported by a departmental training grant (AA07074) and by a research grant to Judson S. Brown (AA01229) from the National Institute on Alcohol Abuse and Alcoholism. James Linakis and David Francisco are thanked for their comments on these studies. Reprint requests should be sent to the author at the Department of Medical Psychology, University of Oregon Health Sciences Center, Portland, Oregon 97201. flavor stimuli, and second, by equating experimental and control groups for overall exposure to ethanol during the extinction phase of the experiment. This latter extension was deemed essential for asserting that the effect depended on the presence of the drug during extinction trials, and was not due merely to some nonspecific effect of exposure to ethanol (e.g., a general change in gustatory sensitivity).

\section{EXPERIMENT 1}

Experiments 1 and 2 each permitted examination of ethanol's impact on the extinction of aversions conditioned (by lithium-chloride toxicosis) to two of the four "primary" tastes-sweet, salty (Experiment 1), sour, and bitter (Experiment 2). In each experiment, two groups of rats first received an aversion conditioning trial with each of two flavor stimuli. Extinction trials were then given such that presentations of one of the flavors were regularly preceded by an ethanol injection, whereas presentations of the other flavor were regularly preceded by a placebo injection. The groups differed in terms of which of the two flavors was preceded by ethanol. Thus, each group served both as an experimental group (with respect to one of the flavors) and as a control group (with respect to the other flavor). Between-group comparisons of the amounts consumed of each flavor provide a means of assessing ethanol's influence on the extinction of taste aversion under conditions of equivalent overall exposure to ethanol. Because primary taste stimuli were employed, the contributions of stimulus generalization could be expected to be minimized.

\section{Method}

Subjects and Apparatus. The subjects were 22 female Simonsen hooded rats, with average weights of $289 \mathrm{~g}$. These rats had previously served in a conditioned-suppression experiment involving 
barpressing for food pellets while food-deprived. All rats had received tone-footshock pairings, several injections of normal saline, and between two and six injections of ethanol (.75 or $1.5 \mathrm{~g} / \mathrm{kg}$ ). Insofar as possible, equal numbers of rats from each of the groups in the conditioned-suppression experiment were assigned to each of the two groups in the present experiment.

The rats were individually housed in wire-mesh cages with ad-lib access to Lab Chow. Water and flavor solutions were presented at room temperature in nalgene test tubes fitted with stainless steel drinking spouts inserted through the front of the home cage.

Procedure. All rats were placed on a water-deprivation schedule 5 days before the first conditioning trial. On the 1st day of this schedule, 20-min access to water was allowed. Thereafter, access was restricted to $10 \mathrm{~min}$ per day.

Taste aversions were conditioned to $.1 \mathrm{M}$ sucrose $(\mathrm{Su})$ and to $.2 \mathrm{M}$ sodium chloride (N) solutions over the next 2 days. On each conditioning day, each rat was allowed to drink one of the two flavored solutions for $10 \mathrm{~min}$ and then received an IP injection of $.6 \mathrm{M}$ lithium chloride $(5 \mathrm{ml} / \mathrm{kg})$ within $5 \mathrm{~min}$. Half of the rats in each group received Su on the 1 st day and $N$ on the 2 nd day; this order was reversed for the remaining animals.

Extinction trials began $48 \mathrm{~h}$ after the second conditioning trial and were repeated every $48 \mathrm{~h}$ until each flavor had been presented twice. Each extinction trial consisted of $10-\mathrm{min}$ access to one of the flavor solutions $30 \mathrm{~min}$ after an IP injection of ethanol $(1.2 \mathrm{~g} / \mathrm{kg}$ in normal saline) or an equivolume injection of normal saline $(10 \mathrm{ml} / \mathrm{kg})$. For Group A-Su $(n=11)$, ethanol preceded $\mathrm{Su}$ extinction trials and saline preceded $\mathrm{N}$ extinction trials. These conditions were reversed for Group A-N $(n=11)$. The order of extinction trials was counterbalanced within each group such that half of the rats received trials in the order ESSE (where E stands for ethanol and $S$ for saline) and half received them in the order SEES. A water-recovery day (10-min access to water only) intervened between conditioning and extinction and between extinction trials.

\section{Results and Discussion}

Figure 1 illustrates the mean amounts of Su (left panel) and $\mathrm{N}$ (right panel) consumed by each group during the conditioning and extinction sessions. As

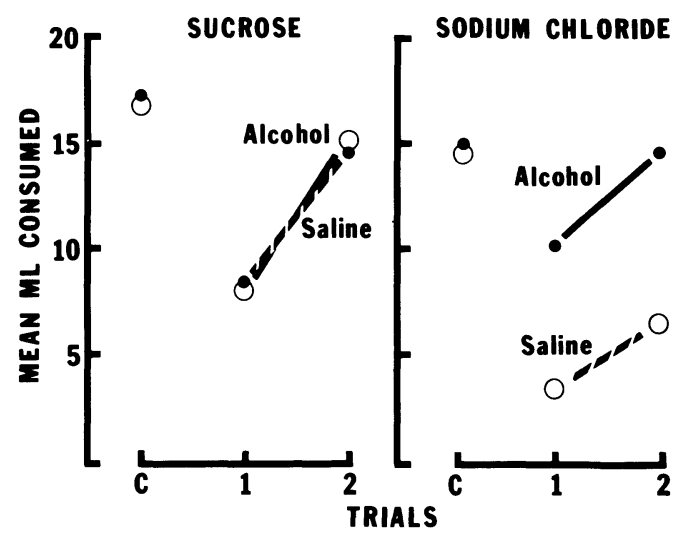

Figure 1. Mean amounts (ml) of sucrose (left panel) and sodium chloride (right panel) consumed on the conditioning trial (C) and two extinction trials. Points connected by solid lines represent fluid intake $30 \mathrm{~min}$ after injection of ethanol $(1.2 \mathrm{~g} / \mathrm{kg})$; points connected by dashed lines represent fluid intake after saline injection. Open symbols denote Group A-Su; closed symbols denote Group A-N. the figure indicates, the groups were reasonably matched for their initial consumptions of these flavors on the conditioning days. There were no group differences on the conditioning days, but there were differences between the amounts consumed on the 1 st and 2nd conditioning days. For each flavor, less was consumed when that flavor was presented on the 2nd day than when it was presented on the 1st day (for Su, Mann-Whitney $\mathrm{U}=8.5$; for $\mathrm{N}, \mathrm{U}=7.5$; ps $<.002)$.

The extinction data reveal several things. First, flavor-lithium pairing reduced the intake of each flavor (i.e., conditioned taste aversions were established), and second, subsequent flavor presentation without lithium produced a loss in that suppression (i.e., the aversions extinguished). More importantly, however, these data show that while Su consumption was unaffected by prior injection of ethanol, consumption of $\mathbf{N}$ was enhanced by ethanol injection on both days (Us $=8.5,11$; ps $<.002$ ). Consumption on water-recovery days did not differ between groups.

Thus, in contrast to Cappell et al.'s report that ethanol retarded the extinction of an aversion to saccharin, Experiment 1 indicated that ethanol did not affect extinction of a sucrose aversion, but enhanced extinction of an aversion to sodium chloride. The depression in intake of the novel flavor on the second conditioning day suggests that these flavor stimuli may have generalized to one another, although part of that depression could also have been due simply to enhanced neophobia as a result of the first poisoning experience (Best \& Batson, 1977; Domjan, 1975). Generalization of extinction might be expected to have accelerated the overall rates of extinction to each of the flavors, but the counterbalanced trial order should have precluded any systematic bias in favor of a particular flavor or particular type of drug trial.

\section{EXPERIMENT 2}

Experiment 2 was designed to assess alcohol's impact on the extinction of aversions conditioned to the other two primary taste stimuli-bitter and sour.

\section{Method}

Subjects and Apparatus. The subjects were 20 naive male Simonsen albino rats, with average weights of $474 \mathrm{~g}$. The housing conditions and test apparatus were those used in Experiment 1.

Procedure. Seven days of restricted fluid intake preceded conditioning. On the 1 st of these days, each rat was allowed 20-min access to a tube filled with water. On each of the next 6 days, access was limited to $10 \mathrm{~min}$. To accustom the rats to the injection procedure, each rat received an IP injection of normal saline $(10 \mathrm{ml} / \mathrm{kg}) 2-3 \mathrm{~h}$ after watering on each of the last two of these preconditioning days.

The conditioning procedure was similar to that used in the first experiment except for the change in flavors and the insertion of 
a water-recovery day (10-min access to water) between conditioning days. As in Experiment 1, two groups of rats ( $n=10 /$ group) each received separate aversion conditioning trials with two flavor stimuli-in this case, $.00007 \mathrm{M}$ quinine hydrochloride (Q) and $.005 \mathrm{M}$ hydrochloric acid (H). Each trial consisted of 10-min access to one of the flavor solutions, followed within $5 \mathrm{~min}$ by an injection of .6 M lithium chloride $(5 \mathrm{ml} / \mathrm{kg})$. Half of the animals in each group received $Q$ on the 1 st conditioning day and half received $\mathbf{H}$.

Three water-recovery days preceded the first extinction trial. The extinction procedure was similar to that used in Experiment 1, with extinction trials occurring at 48-h intervals until each flavor had been presented four times. Each extinction trial involved 10-min access to one of the flavor solutions $30 \mathrm{~min}$ after an IP injection of ethanol $(1.2 \mathrm{~g} / \mathrm{kg}$ in normal saline) or normal saline $(10 \mathrm{ml} / \mathrm{kg})$. For Group A-H, ethanol preceded $\mathrm{H}$ extinction trials and normal saline preceded $Q$ extinction trials. These conditions were reversed for Group A-Q. The order of extinction trials was counterbalanced as in Experiment 1. Ten-minute access to water was permitted on the days between extinction trials.

\section{Results}

The mean amounts of $\mathrm{Q}$ and $\mathrm{H}$ consumed by each group during conditioning and extinction are shown in Figure 2. There were no group differences in the initial intakes of $\mathrm{Q}$ or $\mathrm{H}$ on the conditioning days. For each flavor, less was consumed when it was presented on the 2nd conditioning day than when it was presented on the 1st day, although this reduction was only reliable for $\mathrm{H}(\mathrm{U}=22, \mathrm{p}<.05)$.

The extinction data indicate that ethanol had no effect on the consumption of $\mathrm{H}$, but that it retarded extinction to $Q$. The increase in the amount of $Q$ consumed between the 1st and 4th extinction days was reliably less in the group which received ethanol before each $Q$ trial (Group $A-Q)(U=7.5, p<.002)$. The group differences in $\mathrm{Q}$ consumption were reliably different on each of the last two trials (Us $=13.5$, 9.5; $\mathrm{p}<.02$ ). Consumption on water-recovery days did not differ between groups.

\section{EXPERIMENT 3}

The outcomes of Experiments 1 and 2 combined with that of Cappell et al. (1972) suggest that the effect of alcohol on extinction of conditioned taste aversion depends critically on the flavor of the aversive solution. At the drug dose and flavor concentrations used in these studies, alcohol appears to retard the extinction of saccharin and quinine aversions, has no effect on the extinction of sucrose and hydrochloric-acid aversions, but facilitates the extinction of a sodium-chloride aversion. Although instances of "no effect" might be attributed to a variety of extraneous variables, it is rather difficult to reconcile the occurrence of completely opposite effects with a belief that alcohol exerts a unitary effect on the extinction process. Before considering alternative accounts of such a data pattern, however, it seemed important to replicate the "inconsistent",

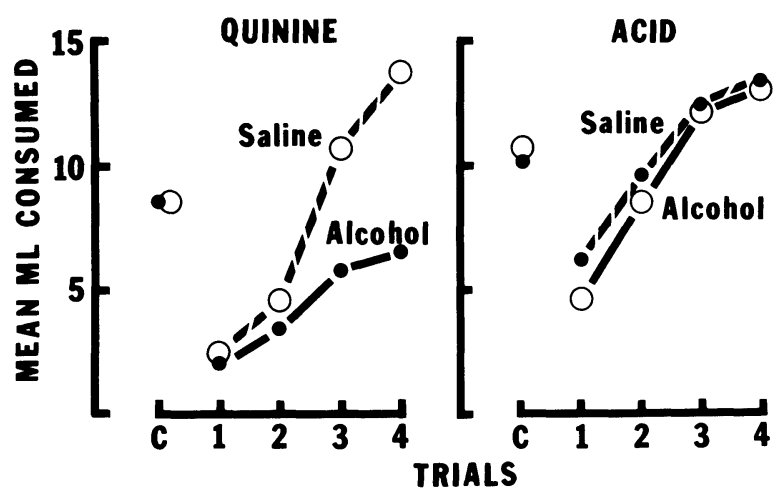

Figure 2. Mean amounts $(\mathrm{ml})$ of quinine hydrochloride (left panel) and hydrochloric acid (right panel) consumed on the conditioning trial $(C)$ and four extinction trials. Points connected by solid lines represent fluid intake $30 \mathrm{~min}$ after injection of ethanol $(1.2 \mathrm{~g} / \mathrm{kg})$; points connected by dashed lines represent fluid intake after saline injection. Open symbols denote Group A-H; closed symbols denote Group A-Q.

finding (i.e., facilitation) in such a way as to rule out some of the less interesting alternative explanations. The finding that alcohol facilitates the extinction of a sodium-chloride aversion was subsequently replicated twice, using a design which did not involve the simultaneous conditioning and extinction of a second flavor. The first replication is described briefly in the next paragraph, and the second replication is formally described below as Experiment 3 .

The first replication used the subjects from Experiment 2. To eliminate residual group differences in the quinine aversions established in that experiment, all rats were first given quinine as their sole fluid for $1 \mathrm{~h} /$ day on each of 5 successive days. Group differences were no longer reliable by the 2 nd day, and consumption over the last 2 days was identical. An equal number of rats from each of the groups in Experiment 2 were then assigned to one of two new groups for the sodium-chloride experiment. All rats were given two pairings of $.2 \mathrm{M}$ sodium chloride with lithium toxicosis followed by three extinction trials. One group received an ethanol injection $(1.2 \mathrm{~g} / \mathrm{kg})$ $30 \mathrm{~min}$ before each extinction trial, whereas the other group received a saline injection. The groups were equated for exposure to ethanol by giving each group an injection of the opposite type 4-5 h after each extinction trial. Water-recovery days separated extinction days. The groups developed equivalent aversions during conditioning, but over the three extinction sessions, the group receiving pretrial injections of ethanol consumed significantly more sodium chloride $(19.9 \mathrm{ml})$ than the group injected with saline $(10.3 \mathrm{ml})(\mathrm{U}=20, \mathrm{p}<.05)$.

The experiment just described indicates that the facilitating effect of ethanol on the extinction of a sodium chloride aversion is not an artifact of the 
two-flavor design of Experiment 1, and is not due to differences in the intrinsic attributes of subjects that have shown facilitation and retardation (e.g., sex, strain, weight). However, both the experiment above and Experiment 1 used subjects that had previously been exposed to ethanol. Since drug novelty has been purported to be an important determinant of alcohol's extinction-retarding abilities (cf. Amit, Ziskind, \& Baum, 1973), the sodium-chloride experiment was replicated in Experiment 3 with drug-naive animals.

\section{Method}

Subjects and Apparatus. The subjects were 15 female Simonsen hooded rats, weighing an average of $318 \mathrm{~g}$ each. Seven of these rats were experimentally naive, whereas the other eight had previously served as subjects in a classical heart-rate conditioning experiment in which they had been exposed to tones, lights, and tailshock. No subject had ever received ethanol. Four each of the naive and experienced rats were assigned to the alcohol group in the present experiment, and the remaining rats were assigned to the saline group. The housing conditions and test apparatus were those used in the previous experiments.

Procedure. The initial fluid-deprivation regime was that described for Experiment 2. Two preconditioning saline injections were also administered as in the previous experiment.

Two sodium-chloride aversion conditioning trials were given $48 \mathrm{~h}$ apart. Each of these trials was identical to the sodiumchloride trial in Experiment 1. Ten-minute access to a $.2 \mathrm{M}$ sodium-chloride solution was followed within $5 \mathrm{~min}$ by an IP injection of $.6 \mathrm{M}$ lithium chloride $(5 \mathrm{ml} / \mathrm{kg})$. A water-recovery session (10-min access to water only) intervened between conditioning sessions, and two water-recovery sessions occurred before the first extinction trial.

Extinction trials were administered at 72 -h intervals until four trials had been given. Each of these trials consisted of $10-\mathrm{min}$ access to the sodium-chloride solution $30 \mathrm{~min}$ after a $1.2 \mathrm{~g} / \mathrm{kg}$ injection of ethanol (alcohol group) or an equivolume injection of normal saline (saline group). Water-recovery sessions occurred on each of the 2 days following each extinction trial. In order to equate groups for overall exposure to ethanol during extinction, each group received an injection of the opposite solution about 26-27 $\mathrm{h}$ after each extinction trial (i.e., 2-3 $\mathrm{h}$ after the first waterrecovery session).

Seventy-two hours after the fourth extinction session, a final extinction trial was given to each group without a pretrial injection. The intent of this procedure was to determine whether the alcohol group's extinction performance would transfer to the nodrug condition.

\section{Results and Discussion}

On the 1st conditioning day, the alcohol and saline groups consumed an average of 15.7 and $15.0 \mathrm{ml}$ of sodium chloride, respectively. The mean amounts consumed by each group on the second trial and on each of the extinction trials are shown in Figure 3. The groups did not differ on either conditioning day. The decline in intake on the 2 nd conditioning day was quite significant (every subject drank less on Day 2 than on Day 1).

Although the alcohol and saline groups did not differ on the first extinction trial, the average amounts consumed by each group diverged over the course of extinction. The increase in consumption between the 1 st and 4th extinction days was reliably greater for the alcohol group than for the saline group $(U=11$, $\mathrm{p}=.05$ ). There were no group differences on any of the water-recovery days.

Thus, Experiment 3 confirms the finding that ethanol facilitates the extinction of an aversion conditioned to the taste of sodium chloride. Moreover, it indicates that this effect can be obtained in ethanolnaive animals. Although the fact that ethanol's effect in the present experiment was not apparent on the first trial, as in Experiment 1, might be attributed to differences in ethanol's novelty, it is more likely due to the fact that a stronger aversion was established by the extra conditioning trial in the present experiment.

The data from the fifth extinction trial, administered without preinjection, are most interesting. As can be seen in Figure 3, although the saline group displayed an even further loss in its aversion to sodium chloride, the alcohol group showed a partial reinstatement of its aversion. Every rat in the alcohol group consumed less on the fifth trial than on the fourth trial, whereas only one rat in the saline group failed to equal or increase its consumption on Trial 5. The difference in the changes between the fourth and fifth trials was quite reliable $(U=0, p<.002)$.

The reinstatement of the alcohol group's extinguished aversion on the final, no-drug trial resembles a recent finding by Cunningham (in press) in a conditioned-suppression paradigm. Rats that had first received Pavlovian fear-conditioning trials without ethanol then received extinction trials with or without ethanol $(1.5 \mathrm{~g} / \mathrm{kg})$. Ethanol had little effect on CS-evoked suppression, which gradually diminished in both drug and no-drug groups during extinction. However, a postextinction test without

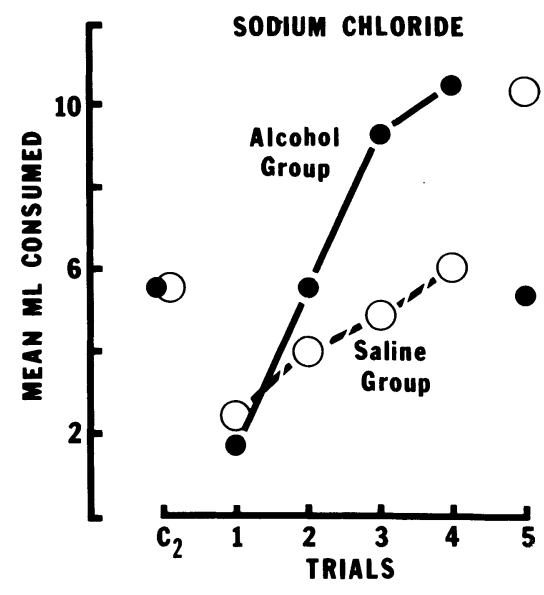

Figure 3. Mean amounts (ml) of sodium chloride consumed on the second conditioning trial $\left(\mathrm{C}_{2}\right)$ and five extinction trials. Injections of ethanol (1.2 $\mathrm{g} / \mathrm{kg}$ ) (alcohol group) or saline (saline group) preceded each of the first four extinction trials. No injection was given before the last extinction trial. 
ethanol revealed substantial reinstatement of suppression to the CS in the group which had received extinction with ethanol. The outcome appeared to be an instance of "state-dependent learning" (cf. Overton, 1972), and evidence was provided to suggest that the learning which occurred was inhibitory. That is, ethanol had become a conditioned inhibitory stimulus as a result of its association with extinction. The removal of ethanol during the postextinction test removed its inhibitory influence, thus producing a reinstatement in suppression to the CS. It is quite possible that a similar process mediated the partial reinstatement of taste aversion obtained in Experiment 3, but the design of this experiment did not permit an independent assessment of ethanol's potential conditioned inhibitory properties. An alternative account of the effect observed here is suggested below.

\section{GENERAL DISCUSSION}

The present experiments indicate that ethanol does not exert a unitary effect on the extinction of conditioned taste aversion. Indeed, depending on the flavor of the aversive solution, ethanol may retard, facilitate, or not affect extinction. This pattern of data defies explanation in terms of most of ethanol's reputed properties. For example, accounts in terms of the supposed aversiveness of ethanol (whether novel or familiar) or its possible abilities to affect motor processes, thirst, fear, or extinctive inhibition only predict an effect upon extinction performance in one direction.

However, it may be possible to explain all of the effects reported here and in Cappell et al.'s (1972) study by assuming that injection of ethanol produces a taste, and that this taste interacts with the tastes of certain orally ingested substances. The general belief that IP injections are capable of producing tastes is supported by findings that injection of certain flavored solutions (saccharin or saccharincyclamate) can be used to condition (Burešova \& Bureš, 1977; Ionescu \& Burešova, 1977) or extinguish (Baum, Foidart, \& Lapointe, 1974) aversions to the same flavor stimuli presented orally. Moreover, an unpublished experiment in the author's laboratory has shown that aversion to an oral solution of ethanol can be produced by pairing ethanol injections with lithium toxicosis.

The assertion that the taste of ethanol may interact with the tastes of the primary flavors in such a way as to produce the present pattern of results is suggested by the work of Martin and Pangborn (1970). In their experiment, the influence of ethanol on perceived taste intensity in human subjects was assessed by presenting ethanol orally in combination with several different concentrations of the primary taste stimuli. The findings of most importance for the present experiments were that ethanol enhanced the bitterness of quinine hydrochloride at all concentrations tested, but that it depressed the saltiness of sodium chloride at certain concentrations (.17 $\mathrm{M}$ and above). Although differences in species, mode of ethanol presentation, and task obviously complicate any detailed comparison of Martin and Pangborn's results with those of the present experiments, the general relevance of their data to the proposed account of ethanol's varied effects on the extinction of taste aversion should be clear. Ethanol's taste appears capable of interacting with the primary tastes in such a way that it might be expected to facilitate the extinction of a sodium chloride aversion (by depressing saltiness), yet retard the extinction of a quinine aversion (by enhancing bitterness). This view could also explain the reinstatement of sodium-chloride aversion following the removal of ethanol in Experiment 3. One might argue that the original extinction trials had involved a generalized (less intense) CS in the alcohol group and that these trials were simply less effective in reducing aversion to the .2-M sodiumchloride stimulus than were trials involving the original CS in the saline group.

The flavor-interaction account of ethanol's impact on taste-aversion extinction has several implications. First, Martin and Pangborn's data suggest that ethanol's effects depend not only on the flavor, but on the concentration of the flavor. In the studies reported here, ethanol might have been found to have no effect on the extinction of aversions conditioned to weaker sodium-chloride or quinine solutions. Conversely, the failure to see an influence of ethanol on extinction of the sucrose and the acid aversions may have been due to the use of relatively weak concentrations of those flavors. Another implication of the flavor-interaction analysis is that these effects should not be restricted to the extinction situation. Ethanol injection might well interact with flavor stimuli to affect neophobic reactions or to change the features of tastes associated with toxicosis during aversion conditioning. Finally, because the ethanol taste is presumably mediated vascularly, all of those variables which are likely to contribute to the magnitude of ethanol's pharmacological effects (e.g., dose, concentration, time since administration, etc.) probably also affect the extent of the ethanolflavor interaction.

If the foregoing analysis of ethanol's impact on taste-aversion extinction is correct, the evidence in favor of ethanol's reputed extinction-retarding abilities is reduced to one general type of situationnamely, an instrumental learning situation involving a locomotor response (Barry, Wagner, \& Miller, 1962; Baum, 1969, 1971; Skurdal et al., 1975). Although this may reflect a very selective influence 
of ethanol on a particular kind of extinctive inhibition, none of these instrumental learning studies completely eliminated the possibility that ethanol merely enhanced locomotor activity.

The possibility that nonoral administration of ethanol produces a taste which may affect the tastes of orally ingested substances poses an obvious problem for the study of ethanol's pharmacological properties in the taste-aversion paradigm. The present analysis suggests that ethanol affects aversions to oral solutions at a peripheral level, by actually altering the nature of the flavor stimulus. The drug's reputed psychoactive properties play no part in this account, and in fact, given this account, it is not entirely clear how one could determine unambiguously whether any of ethanol's centrally mediated effects influenced conditioned taste aversion. One possibility might be to focus on manipulations which would be expected to change ethanol's psychoactive properties, but which would not be expected to alter its effects on taste. By comparing treated and nontreated subjects following ethanol injection, one might be able to make conclusions about ethanol's psychoactive effects on conditioned taste aversion.

Although the relative rapidity with which ethanol is absorbed after injection may especially promote its ability to produce a strong taste, it is quite possible that other drugs also produce tastes which might interact with those of orally ingested substances. The present experiments encourage an increased awareness of that possibility and suggest that some of the problems which it poses for the study of ethanol's properties may be more general problems for the study of pharmacological agents on conditioned taste aversion. It is only rarely that the potential taste-altering effects of parenterally administered drugs have even been considered in such experiments (e.g., Coil, Hankins, Jenden, \& Garcia, 1978).

The possibility that some of the drugs which are capable of functioning as USs for taste-aversion learning (including ethanol) may also produce tastes suggests another in which taste-aversion learning may be affected by parenterally mediated tastes. It is possible that those tastes may actually compete with the tastes of orally administered substances for association with whatever features of the drug are responsible for aversion learning. Drug-administration variables might affect level of aversion to an oral solution not only because they affect the drug's pharmacological properties, but because they affect the salience of the drug's taste properties as well. For example, Coussens' (1974) report that intravenous administration of amphetamine produced a weaker aversion to saccharin than did an equivalent dose of the drug injected IP may reflect differential overshadowing of the taste of saccharin by the taste of amphetamine, and not the differential aversiveness of drug effects by each route. An extension of this analysis may also provide an alternative account of some of the studies which have shown reduced aversion learning following preexposure to a drug US (cf. Gamzu, 1977). Specifically, during US preexposure, the drug's taste may become so strongly associated with its aversion-producing features that subsequent conditioning to an oral solution is "blocked"' (cf. Kamin, 1969).

\section{REFERENCES}

Amit, Z., \& Baum, M. Comment on the increased resistanceto-extinction of an avoidance response induced by certain drugs. Psychological Reports, 1970, 27, 310.

AMIt, Z., Ziskind, D., \& BAUM, M. Drug effects and avoidance extinction in rats: A test of the drug novelty hypothesis using ethanol. Animal Learning \& Behavior, 1973, 1, 41-43.

BARRY, H., III, WAGNer, A. R., \& Miller, N. E. Effects of alcohol and amobarbital on performance inhibited by experimental extinction. Journal of Comparative and Physiological Psychology, 1962, 55, 464-468.

BAum, M. Paradoxical effect of alcohol on the resistance to extinction of an avoidance response in rats. Journal of Comparative and Physiological Psychology, 1969, 69, 238-240.

BAUM, M. Effect of alcohol on the acquisition and resistanceto extinction of avoidance responses in rats. Psychological Reports, 1970, 26, 759-765.

BAUM, M. Effect of alcohol on the resistance-to-extinction of an avoidance response: Replication in mice. Physiology \& Behavior, 1971, 6, 307-309.

Baum, M., Foidart, D. S., \& LApointe, A. Rapid extinction of a conditioned taste aversion following unreinforced intraperitoneal injection of the fluid CS. Physiology \& Behavior, 1974, 12, 871-873.

Best, M. R., \& Batson, J. D. Enhancing the expression of flavor neophobia: Some effects of the ingestion-illness contingency. Journal of Experimental Psychology: Animal Behavior Processes, 1977, 3, 132-143.

Burešova, O., \& BurEš, J. The effect of anesthesia on acquisition and extinction of conditioned taste aversion. Behavioral Biology, 1977, 20, 41-50.

Cappell, H., LeBlanc, A. E., \& Endrenyi, L. Effects of chlordiazepoxide and ethanol on the extinction of a conditioned taste aversion. Physiology \& Behavior, 1972, 9, 167-169.

Coil, J. D., Hankins, W. G., Jenden, D. J., \& Garcia, J. The attenuation of a specific cue-to-consequence association by antiemetic agents. Psychopharmacology, 1978, 56, 21-25.

Coussens, W. Conditioned taste aversion: Route of drug administration. In J. M. Singh \& H. Lal (Eds.), Drug addiction (Vol. 3). New York: Stratton Intercontinental Medical Book Corporation, 1974.

Cunningham, C. L. Alcohol as a cue for extinction: State dependency produced by conditioned inhibition. Animal Learning \& Behavior, in press.

Domuan, M. Poison-induced neophobia in rats: Role of stimulus generalization of conditioned taste aversion. Animal Learning \& Behavior, 1975, 3, 205-211.

GAMzU, E. The multifaceted nature of taste-aversion-inducing agents: Is there a single common factor? In L. M. Barker, M. R. Best, \& M. Domjan (Eds.), Learning mechanisms in food selection. Waco, Texas: Baylor University Press, 1977.

Ionescu, E., \& Burešova, O. Effects of hypothermia on the acquisition of conditioned taste aversion in rats. Journal of Comparative and Physiological Psychology, 1977, 91. 1297-1307. 
Kamin, L. J. Predictability, surprise, attention, and conditioning. In B. A. Campbell \& R. M. Church (Eds.), Punishment and aversive behavior. New York: Appleton-Century-Crofts, 1969.

Martin, S., \& Pangborn, R. M. Taste interaction of ethyl alcohol with sweet, salty, sour, and bitter compounds. Journal of the Science of Food and Agriculture, 1970, 21, 653-655.

Overton, D. A. State-dependent learning produced by alcohol and its relevance to alcoholism. In B. Kissin \& $\mathbf{H}$. Begleiter (Eds.), The biology of alcoholism (Vol. 2). New York: Plenum Press, 1972.
Skurdal, A. J., Eckardt, M. J., \& Brown, J. S. The effects of alcohol on escape learning and on regular and punished extinction in a self-punitive situation with rats. Physiological Psychology, 1975, 3, 29-34.

(Received for publication May 8, 1978; accepted June 26, 1978.) 